\title{
Effect of Hydrothermal Treatment and Doping on the Microstructural Features of Sol-Gel Derived $\mathrm{BaTiO}_{3} \mathrm{Nanoparticles}$
}

\author{
Nico Zamperlin ${ }^{1, *}$, Riccardo Ceccato ${ }^{1}\left(\mathbb{D}\right.$, Marco Fontana $^{1,2}$, Alessandro Pegoretti ${ }^{1,3} \mathbb{C}$, Andrea Chiappini ${ }^{4}$ \\ and Sandra Dirè ${ }^{1}$ (I) \\ 1 Department of Industrial Engineering, University of Trento, Via Sommarive 9, 38123 Trento, Italy; \\ riccardo.ceccato@unitn.it (R.C.); marco.fontana@santannapisa.it (M.F.); alessandro.pegoretti@unitn.it (A.P.); \\ sandra.dire@unitn.it (S.D.) \\ 2 Institute of Mechanical Intelligence, Scuola Superiore Sant'Anna, Piazza Martiri della Libertà 33, 56127 Pisa, Italy \\ 3 National Interuniversity Consortium of Materials Science and Technology (INSTM), Via G. Giusti, 9, \\ 50121 Firenze, Italy \\ 4 Institute of Photonics and Nanotechnologies (IFN-CNR), CSMFO Laboratory and Fondazione Bruno \\ Kessler (FBK) Photonics Unit, Via alla Cascata 56/C, Povo, 38123 Trento, Italy; chiappini@fbk.eu \\ * Correspondence: nico.zamperlin@unitn.it
}

Citation: Zamperlin, N.; Ceccato, R.; Fontana, M.; Pegoretti, A.; Chiappini, A.; Dirè, S. Effect of Hydrothermal Treatment and Doping on the Microstructural Features of Sol-Gel Derived $\mathrm{BaTiO}_{3}$ Nanoparticles. Materials 2021, 14, 4345. https:// doi.org/10.3390/ma14154345

Academic Editor: Aivaras Kareiva

Received: 23 June 2021

Accepted: 29 July 2021

Published: 3 August 2021

Publisher's Note: MDPI stays neutral with regard to jurisdictional claims in published maps and institutional affiliations.

Copyright: (C) 2021 by the authors. Licensee MDPI, Basel, Switzerland. This article is an open access article distributed under the terms and conditions of the Creative Commons Attribution (CC BY) license (https:// creativecommons.org/licenses/by/ $4.0 /)$.

\begin{abstract}
Barium Titanate $\left(\mathrm{BaTiO}_{3}\right)$ is one of the most promising lead-free ferroelectric materials for the development of piezoelectric nanocomposites for nanogenerators and sensors. The miniaturization of electronic devices is pushing researchers to produce nanometric-sized particles to be embedded into flexible polymeric matrices. Here, we present the sol-gel preparation of crystalline $\mathrm{BaTiO}_{3}$ nanoparticles (NPs) obtained by reacting barium acetate $\left(\mathrm{Ba}\left(\mathrm{CH}_{3} \mathrm{COO}\right)_{2}\right)$ and titanium (IV) isopropoxide $\left(\mathrm{Ti}\left(\mathrm{O}^{\mathrm{i}} \mathrm{Pr}\right)_{4}\right)$. The reaction was performed both at ambient conditions and by a hydrothermal process carried on at $200{ }^{\circ} \mathrm{C}$ for times ranging from 2 to $8 \mathrm{~h}$. Doped $\mathrm{BaTiO}_{3}$ nanoparticles were also produced by addition of $\mathrm{Na}, \mathrm{Ca}$, and $\mathrm{Bi}$ cations. The powders were annealed at $900{ }^{\circ} \mathrm{C}$ in order to improve NPs crystallinity and promote the cubic-to-tetragonal $(\mathrm{c} \longrightarrow \mathrm{t}$ ) phase transformation. The microstructural features of nanoparticles were investigated in dependence of both the hydrothermal reaction time and the presence of dopants. It is found that short hydrothermal treatment $(2 \mathrm{~h}) \mathrm{can}$ produce $\mathrm{BaTiO}_{3}$ spherical and more homogeneous nanoparticles with respect to longer hydrothermal treatments $(4 \mathrm{~h}, 6 \mathrm{~h}, 8 \mathrm{~h})$. These particles $(2 \mathrm{~h})$ are characterized by decreased dimension (approx. $120 \mathrm{~nm}$ ), narrower size distribution and higher tetragonality (1.007) in comparison with particles prepared at ambient pressure (1.003). In addition, the short hydrothermal treatment $(2 \mathrm{~h})$ produces particles with tetragonality comparable to the one obtained after the longest process $(8 \mathrm{~h})$. Finally, dopants were found to affect to different extents both the $\mathrm{c} \longrightarrow \mathrm{t}$ phase transformation and the crystallite sizes.
\end{abstract}

Keywords: piezoceramics; nanoparticles; sol-gel; hydrothermal treatment; doping

\section{Introduction}

During the last few years, there has been an increasing interest in the development of piezoelectric composite materials for energy harvesting, actuators, and soft sensors applications. The coupling of piezo-ceramic fillers with polymeric matrices, such as polydimethylsiloxane (PDMS) and polyvinylidenefluoride (PVDF), can combine high dielectric and piezoelectric properties of ceramics with flexibility and softness of polymers [1-3]. To get high performance piezo-composites, the production and development of piezoceramics plays a key role. Up to the last decade, one of the most widely used piezoelectric materials was lead-zirconium titanate (PZT) [4,5], a metallic oxide with a perovskitic structure that possesses very high dielectric and piezoelectric properties [6,7]. However, there are several issues concerning this material due to the presence of lead $(\mathrm{Pb}) . \mathrm{Pb}$ is harmful both for the environment and human health; moreover, additional problems are related to its correct 
disposal. In this scenario, in the last few years, researchers have been pushing on to find a valid, high performance, lead-free alternative to PZT $[8,9]$. The most widely studied $\mathrm{Pb}$-free piezoelectric ceramics are titanates (in particular barium-strontium titanate $\left(\mathrm{Ba}_{1-\mathrm{x}} \mathrm{Sr}_{\mathrm{x}} \mathrm{TiO}_{3}\right)$ and barium titanate $\left(\mathrm{BaTiO}_{3}\right)$ ) [10] and niobates (lithium niobate, $\mathrm{LiNbO}_{3}$, sodium niobate $\mathrm{NaNbO}_{3}$, and potassium niobate $\left.\mathrm{KNbO}_{3}\right)[9,11,12]$.

$\mathrm{BaTiO}_{3}(\mathrm{BT})$ is one of the most promising lead-free perovskitic oxides. It was largely employed before the discovery of PZT and it is now facing a renewed interest due to its high permittivity and ferroelectric and piezoelectric properties [13]. Barium titanate presents the typical perovskitic structure $\mathrm{ABO}_{3}$ (A and $\mathrm{B}$ are metallic cations) that can present different crystalline lattices, the most common being the cubic, tetragonal, and orthorhombic structures. In the ideal cubic structure, 12 -fold coordinated A cations are arranged on the corners of a cube surrounding a $\mathrm{BO}_{6}$ octahedron, where $\mathrm{B}$ cation sits in the body-centered positions and oxygen anions are placed in the face-centered positions [14]. Thanks to its structure, it can accommodate a large variety of metallic ions [15] that can be exploited for enhancing and tuning the dielectric and piezoelectric properties of the final material. Dopants can occupy both the A or B site depending on their charge and ionic radius $[15,16]$. The BT piezoelectric behavior depends on its crystalline structure. In fact, the presence of a net dipole moment is responsible for a charge displacement into the crystal lattice [17]. The cubic structure is centrosymmetric and does not present the net dipole moment. On the contrary, the tetragonal structure is elongated along the c-axis and this deformation is responsible for a local charge displacement and, consequently, for a net dipole moment [18]. The tetragonality is evaluated through the $c / a$ ratio; the higher the tetragonality, the more pronounced the piezoelectric effect.

In the preparation of high-performance piezo-composites, one of the main issues is related to a generally poor compatibility between the ceramic nanoparticles (NPs) and the polymeric matrix, which does not allow a good dispersion of the filler, leading to a lower improvement of the piezoelectric performances. However, the surface functionalization of ceramic powders can improve the filler-matrix compatibility and enhance the dielectric and piezoelectric performance of the final product [19-22]. The yield of chemical modification depends on both the surface area and the surface reactivity of fillers, which can be improved through wet chemical syntheses of ceramic NPs.

The preparation of $\mathrm{BaTiO}_{3}$ nanoparticles (NPs) in a solution presents several advantages over the classic solid-state production route, in particular in terms of energy cost. The solid-state process involves the mixing of barium and titanium oxides powders, a ball milling step, and finally, calcination at very high temperatures $\left(1100-1400{ }^{\circ} \mathrm{C}\right)[23,24]$. Powders from solid state route are characterized by low homogeneity, impurities, and broad particle size distribution. Conversely, high purity homogeneous particles, with narrow size distribution and improved surface area, are obtained at lower temperatures by the sol-gel process. Accordingly, the low temperature hydrothermal method has been widely explored for the production of titanates and other perovskitic structures [25-27]. The sol-gel synthesis of barium titanate at both ambient pressure and hydrothermal conditions exploits different precursors and solvents. The most widely used precursors are $\mathrm{TiO}_{2}$ particles and $\mathrm{Ba}(\mathrm{OH})_{2}[28,29]$, titanium and barium chlorides [30], and titanium alkoxides [31-33]. The alkoxide-based sol-gel production route of barium titanate particles is based on the controlled hydrolysis-condensation of the precursor through the addition of organic additives, such as carboxylic acids. The process is usually carried out in a strong alkaline environment, since barium titanate formation is favored at $\mathrm{pH}>12-13$. The mechanism of formation of barium titanate starting from alkoxide precursor is still point of debate, but it is generally accepted that the addition of a carboxylic acid to an alcoholic solution of $\operatorname{Ti}\left(\mathrm{O}^{\mathrm{i}} \mathrm{Pr}\right)_{4}$ promotes the formation of a titanyl-acylate complex $\mathrm{Ti}(\mathrm{OR})_{\mathrm{x}}(\mathrm{OAc})_{\mathrm{y}}[34,35]$, which reacts after the addition of the aqueous Ba-sol, leading to the formation of $\mathrm{Ti}(\mathrm{OH})_{\mathrm{x}}(\mathrm{OAc})_{\mathrm{y}}$ species. The addition of a strong base $(\mathrm{KOH}, \mathrm{NaOH})$ to the Ba-Ti sol transforms $\mathrm{Ti}(\mathrm{OH})_{\mathrm{x}}(\mathrm{OAc})_{\mathrm{y}}$ complexes in $\mathrm{Ti}(\mathrm{OH})_{6}{ }^{2}-$ species that link to $\mathrm{Ba}^{2+}$ ions leads to crystalline $\mathrm{BaTiO}_{3}$ precipitation [28,32]. Moreover, the hydrothermal treatment can be applied to the sol-gel 
synthesis. This process offers several advantages over the classic sol-gel route at ambient pressure, reducing the processing time and costs and producing very fine powders with good crystallinity, homogeneity, and controlled size.

In this work, undoped and doped barium titanate nanoparticles were prepared by the sol-gel route at ambient and hydrothermal conditions. The main goal of this work is to evaluate the effect of the synthesis parameters, namely the duration of the hydrothermal treatment and the addition of dopants, on BT NPs microstructural features. Chemical, structural, and microstructural properties of the obtained powders were studied by inductive coupled plasma-optical emission spectroscopy (ICP-OES), Fourier transform infrared spectroscopy (FTIR), scanning electron microscopy (SEM), X-ray diffraction (XRD), Raman spectroscopy, and thermogravimetric and differential thermal analyses (TGA-DTA).

\section{Materials and Methods}

\subsection{Materials}

Reagent grade titanium (IV) isopropoxide $\mathrm{Ti}\left(\mathrm{O}^{\mathrm{i}} \mathrm{Pr}\right)_{4}$ (Sigma-Aldrich, Saint Louis, MO, USA, CAS 546-68-9), barium acetate $\mathrm{Ba}\left(\mathrm{CH}_{3} \mathrm{COO}\right)_{2}$ (Analyticals Carlo Erba, Milan, Italy CAS 543-80-6), sodium acetate $\mathrm{NaCH}_{3} \mathrm{COO}$ (Analyticals Carlo Erba, Milan, Italy, CAS 127-09-3), calcium nitrate tetrahydrate $\mathrm{Ca}\left(\mathrm{NO}_{3}\right)_{2} 4 \mathrm{H}_{2} \mathrm{O}$ (Sigma Aldrich, Saint Louis, MO, USA, CAS 13477-34-4), bismuth nitrate pentahydrate $\mathrm{Bi}\left(\mathrm{NO}_{3}\right)_{3} 5 \mathrm{H}_{2} \mathrm{O}$ (Sigma Aldrich, Saint Louis, MO, USA, CAS 10035-06-0), potassium hydroxide $\mathrm{KOH}$ (VWR International, Milan, Italy CAS 1310-58-3), glacial acetic acid $\mathrm{CH}_{3} \mathrm{COOH}$ (ITW Reagents, Darmstadt, Germany, CAS 64-19-7), and absolute ethanol $\mathrm{C}_{2} \mathrm{H}_{5} \mathrm{OH}$ (Merck KGaA, Darmstadt, Germany, CAS 64-17-5) were employed for powders synthesis. As a comparison, commercial barium titanate powders were purchased from Acros Organics (Geel, Belgium) and the sample was labeled BT_comm.

\subsection{Synthesis of BT Powders}

BT powders were produced modifying the procedure of Hwang et al. [34,35]. The reaction was carried out under nitrogen to avoid $\mathrm{BaCO}_{3}$ precipitation. $\mathrm{Ti}\left(\mathrm{O}^{\mathrm{i}} \mathrm{Pr}\right)_{4}(0.01$ moles $)$ was reacted with glacial acetic acid and absolute ethanol in 1:4:8 molar ratio and the solution was kept under stirring for $1 \mathrm{~h} . \mathrm{Ba}\left(\mathrm{CH}_{3} \mathrm{COO}\right)_{2}(0.011$ moles, $\mathrm{Ba} / \mathrm{Ti}=1.1$ molar ratio $)$ was reacted with $\mathrm{CH}_{3} \mathrm{COOH}(0.022 \mathrm{~mol}$, Ba:acetic acid $=1: 2$ molar ratio $)$ in $5 \mathrm{~mL}$ of distilled water; the clear solution was slowly added to the Ti-sol and the mixture was kept under stirring at room temperature for $1 \mathrm{~h}$. Then, $\mathrm{KOH}(3 \mathrm{~N})$ solution was added until a $\mathrm{pH}$ higher than 13 was reached. The milky suspension was vigorously stirred for $7 \mathrm{~h}$ at $45^{\circ} \mathrm{C}$ under $\mathrm{N}_{2}$ flux, and then was stirred at RT overnight. The powders were collected through centrifugation at $4000 \mathrm{rpm}$, washed with distilled water until neutral $\mathrm{pH}$, and finally dried in an oven at $80^{\circ} \mathrm{C}$ for $4-6 \mathrm{~h}$ and then overnight at room temperature (RT). The dried powders were annealed at $900{ }^{\circ} \mathrm{C}$ for $4 \mathrm{~h}$. As-prepared and thermally treated sol-gel samples are labeled BT and BT_900, respectively.

A similar procedure was adopted for the preparation of BT powders under hydrothermal conditions. Ti and Ba sols were mixed, and the resultant solution was kept under stirring for $1 \mathrm{~h}$ in nitrogen. Then, $\mathrm{KOH}$ solution was added to the Ti-Ba solution; the milky mixture was immediately transferred into a (poly-tetrafluoroethylene) PTFE-lined stainlesssteel reactor and heated at $200{ }^{\circ} \mathrm{C}$ for various times $(2,4,6$ and $8 \mathrm{~h})$. The heating was stopped, and the autoclave was left to naturally cool to room temperature. The powders were collected by centrifugation, washed, and dried at $80^{\circ} \mathrm{C}$ for $4-6 \mathrm{~h}$ and overnight at RT. As-prepared and annealed powders are labeled BT_H and BT_H_900, respectively. The doped powders were also prepared by $2 \mathrm{~h}$ hydrothermal treatment, by dissolving into the Ba-sol the stoichiometric amounts of sodium acetate, calcium nitrate and bismuth nitrate in order to obtain a theoretical composition $\mathrm{Ba}_{0.9} \mathrm{X}_{0.1} \mathrm{TiO}_{3}$ (where $\mathrm{X}=\mathrm{Na}^{+}, \mathrm{Ca}^{2+}$, $\mathrm{Bi}^{3+}$ ). Undoped and doped dried powders were annealed at $900{ }^{\circ} \mathrm{C}$ for $4 \mathrm{~h}$. Doped samples are labeled BT_H_X_900 (X = Na, Ca, Bi or NaBi). Table 1 summarizes sample labeling, processing conditions, eventual doping, and annealing. 
Table 1. Sample labeling and description of production method.

\begin{tabular}{|c|c|c|c|}
\hline Sample & Hydrothermal Treatment & Doping * & Annealing \\
\hline BT & - & - & - \\
\hline BT_900 & - & - & $900{ }^{\circ} \mathrm{C}, 4 \mathrm{~h}$ \\
\hline BT_H & $200^{\circ} \mathrm{C}, 2 \mathrm{~h}$ & - & - \\
\hline BT_H_900 & $200^{\circ} \mathrm{C}, 2 \mathrm{~h}$ & - & $900{ }^{\circ} \mathrm{C}, 4 \mathrm{~h}$ \\
\hline BT_H4h_900 & $200^{\circ} \mathrm{C}, 4 \mathrm{~h}$ & - & $900{ }^{\circ} \mathrm{C}, 4 \mathrm{~h}$ \\
\hline BT_H6h_900 & $200^{\circ} \mathrm{C}, 6 \mathrm{~h}$ & - & $900{ }^{\circ} \mathrm{C}, 4 \mathrm{~h}$ \\
\hline BT_H8h_900 & $200^{\circ} \mathrm{C}, 8 \mathrm{~h}$ & - & $900{ }^{\circ} \mathrm{C}, 4 \mathrm{~h}$ \\
\hline BT_H_Na_-900 & $200^{\circ} \mathrm{C}, 2 \mathrm{~h}$ & $\mathrm{Na}(10 \% \mathrm{~mol})$. & $900{ }^{\circ} \mathrm{C}, 4 \mathrm{~h}$ \\
\hline BT_H_Ca_900 & $200^{\circ} \mathrm{C}, 2 \mathrm{~h}$ & $\mathrm{Ca}(10 \% \mathrm{~mol})$. & $900{ }^{\circ} \mathrm{C}, 4 \mathrm{~h}$ \\
\hline BT_H_Bi_900 & $200^{\circ} \mathrm{C}, 2 \mathrm{~h}$ & $\mathrm{Bi}(10 \% \mathrm{~mol})$. & $900{ }^{\circ} \mathrm{C}, 4 \mathrm{~h}$ \\
\hline 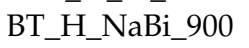 & $200^{\circ} \mathrm{C}, 2 \mathrm{~h}$ & $\mathrm{Na}(5 \%$ mol.); $\mathrm{Bi}(5 \%$ mol.) & $900{ }^{\circ} \mathrm{C}, 4 \mathrm{~h}$ \\
\hline
\end{tabular}

${ }^{*}$ Doping \% is expressed with respect to the total amount of element $\mathrm{A}$ in $\mathrm{ABO}_{3}$ structure.

\subsection{Thermal Treatment}

As-prepared powders from both sol-gel synthesis at ambient pressure and in hydrothermal conditions have been annealed at $900{ }^{\circ} \mathrm{C}$ for $4 \mathrm{~h}$ (heating rate $10^{\circ} \mathrm{C} / \mathrm{min}$ ) in a tubular $\mathrm{SiO}_{2}$ furnace (Heraeus $\mathrm{GmbH}$, Hanau, Germany) in order to remove any organic residual and promote the cubic to tetragonal $(\mathrm{c} \longrightarrow \mathrm{t})$ transformation.

\subsection{Characterization}

TGA-DTA curves were collected with a Netzsch STA 409 thermobalance (NetzschGerätebau $\mathrm{GmbH}$, Selb, Germany), between 20 and $1000{ }^{\circ} \mathrm{C}$, at a $10^{\circ} \mathrm{C} / \mathrm{min}$ heating rate in flowing air. Chemical analysis was carried out by ICP-OES using a Spectro Ciros Instrument (Spectro Analytical Instruments GmbH \& Co, Klevee, Germany). Samples (25 mg) were dissolved in $5 \mathrm{~mL}$ of concentrated $\mathrm{HCl}$ with the addition of few droplets of $\mathrm{H}_{2} \mathrm{O}_{2}$, and de-ionized (DI) water was added up to a final volume of $50 \mathrm{~mL}$. M4M-standards were used for the quantitative analysis of $\mathrm{Ba}, \mathrm{Ti}$, and dopant elements. FTIR spectra were collected in transmission mode on $\mathrm{KBr}$ pellets of both as-prepared and annealed particles using a Thermo Nicolet Avatar 330 FT-IR spectrophotometer (Thermo Electron Corporation, Waltham, MA, USA) using the following parameters: range $4000-400 \mathrm{~cm}^{-1}, 64$ scans, resolution $4 \mathrm{~cm}^{-1}$. Nitrogen adsorption isotherms were acquired with a Micromeritics ASAP 2010 instrument (Micromeritics). Brunauer-Emmett-Teller (BET) and Barrett-JoynerHalenda $(\mathrm{BJH})$ models were used, respectively, for the determination of specific surface area and pore size distribution. SEM micrographs of annealed powders were acquired with a Carl Zeiss Gemini Supra 40 field emission scanning electron microscope (FE-SEM) (Zeiss, Oberkochen, Germany), with an accelerating voltage of $10 \mathrm{kV}$ at $20,000 \times, 50,000 \times$, and $80,000 \times$ magnification using secondary electrons as main signal. Particle size analysis was performed by ImageJ software (https:/ /imagej.nih.gov/ij/, accessed on 29 July 2021). XRD analyses were performed with a Rigaku III-D Max diffractometer (Rigaku, Tokyo, Japan), using $\mathrm{CuK} \alpha$ radiation and a curved graphite monochromator in the diffracted beam. All samples were analyzed using the following parameters: $40 \mathrm{kV}, 30 \mathrm{~mA}, 10^{\circ}<2 \theta<90^{\circ}$, step $0.05^{\circ}$, acquisition time $2 \mathrm{~s}$. The phase analysis was performed using JADE8 software (Materialsdata Inc., MDI, Livermore, CA, USA). Patterns were then processed with MAUD software [36] (https: / / maud.radiographema.eu, accessed on 18 March 2021) to evaluate the phase composition, lattice parameters, and crystallite size. In order to take into proper account the instrumental broadening of the peaks during the deconvolution procedure, a calibration was performed using $\mathrm{KCl}$ as a reference material. Raman measurements were carried out using a LabRAM Aramis (Horiba Jobin-Yvon) equipped with an optical microscope and a $100 \times$ objective. A diode-pumped solid-state laser source of $532 \mathrm{~nm}$ was used for the excitation of the Raman signal that was detected with an air-cooled charge coupled device. A diffraction grating with 1800 lines $\mathrm{mm}^{-1}$ was used for the collection of 
all Raman spectra with an overall spectral resolution of $1 \mathrm{~cm}^{-1}$. Raman spectra have been acquired with an overall acquisition time of $4 \mathrm{~s}$ by setting the laser power at $3 \mathrm{~mW}$.

\section{Results and Discussion}

Preliminary experiments have been done in order to optimize the sol-gel synthesis parameters, in particular the molar ratio between $\mathrm{Ti}$ and Ba precursors (Ba/Ti ratio). It was found that that $\mathrm{Ba} / \mathrm{Ti}$ ratio equal to 1 led to the formation of several metastable (low barium) Ba-Ti oxides, such as $\mathrm{BaTi}_{2} \mathrm{O}_{5}, \mathrm{Ba}_{2} \mathrm{Ti}_{5} \mathrm{O}_{11}$, and $\mathrm{Ba}_{4} \mathrm{Ti}_{13} \mathrm{O}_{30}$, in agreement with previous reports [37,38]. On the contrary, a $\mathrm{Ba} / \mathrm{Ti}$ ratio slightly higher than 1 reduced the formation of these undesired phases leading to pure $\mathrm{BaTiO}_{3}$. Accordingly, in this work, $\mathrm{a} \mathrm{Ba} / \mathrm{Ti}$ ratio equal to 1.1 was used for sol-gel syntheses both at ambient pressure and in hydrothermal conditions. For doped samples, the ratio $(\mathrm{Ba}+$ dopant $) / \mathrm{Ti}=1.1$ was used, since the dopant element partially substitutes the Ba-cation in the perovskite A-site. As-prepared powders were annealed in order to promote the formation of tetragonal phase. Figure 1 shows the results of TGA-DTA analysis of BT powders in the range $20-1000{ }^{\circ} \mathrm{C}$. Two weight loss steps are visible in the TG curve: the main one (about $6 \%$ ) is found in the range $20-800{ }^{\circ} \mathrm{C}$, and it is attributed to both release of organic residuals and condensation of surface hydroxyl groups; between 800 and $900{ }^{\circ} \mathrm{C}$, a second weak effect (about $1 \%$ ) is probably ascribable to the release of lattice hydroxyl defects typically present in samples prepared by wet chemical methods [39]. The sample appears thermally stable above $900{ }^{\circ} \mathrm{C}$. According to Ashiri [40], who studied the thermal evolution of solgel barium titanate powders, above $800{ }^{\circ} \mathrm{C}$, barium carbonate is removed, and the BT phase transformation is completed. The DTA curve shows an exothermic peak centered at $386^{\circ} \mathrm{C}$, which is attributed to the combustion of organics and the decomposition of $\mathrm{BaCO}_{3}$ and intermediate phases [41]. An exothermal effect is observed at $740{ }^{\circ} \mathrm{C}$ and attributed to the crystallization of BT tetragonal phase [42]. In fact, the cubic-to-tetragonal phase transformation is reported at around $850{ }^{\circ} \mathrm{C}$ [40], but the tetragonal phase starts to appear above $600{ }^{\circ} \mathrm{C}$ [43] probably due to intermediate structures in a local environment of the lattice. According to the result of thermal analyses, annealing at $900^{\circ} \mathrm{C}$, with isothermal steps of $4 \mathrm{~h}$, was selected for all samples in order to decompose unwanted phases and complete the cubic-to-tetragonal transformation.

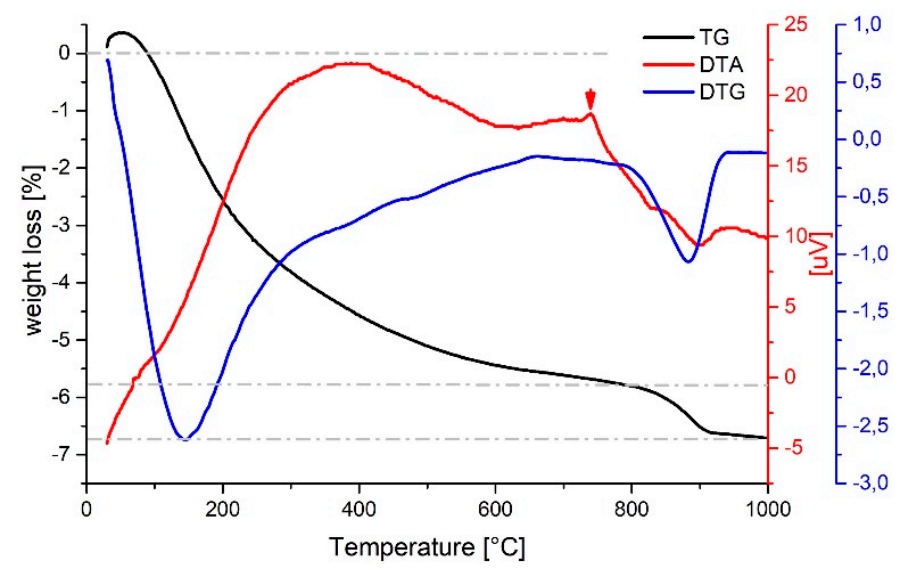

Figure 1. TGA-DTA curves of BT powders.

Figure 2 shows the FTIR spectra of as-prepared BT powders produced via sol-gel synthesis both at ambient pressure and under hydrothermal conditions. Typical M-O vibrations are found below $800 \mathrm{~cm}^{-1}$. In particular, broad signals due to Ti-O stretching and Ti-O-Ti bending signals are found, respectively, at 550 and $425 \mathrm{~cm}^{-1}$ [40,44] in both samples, but they are narrower and more intense in the BT_H spectrum. 


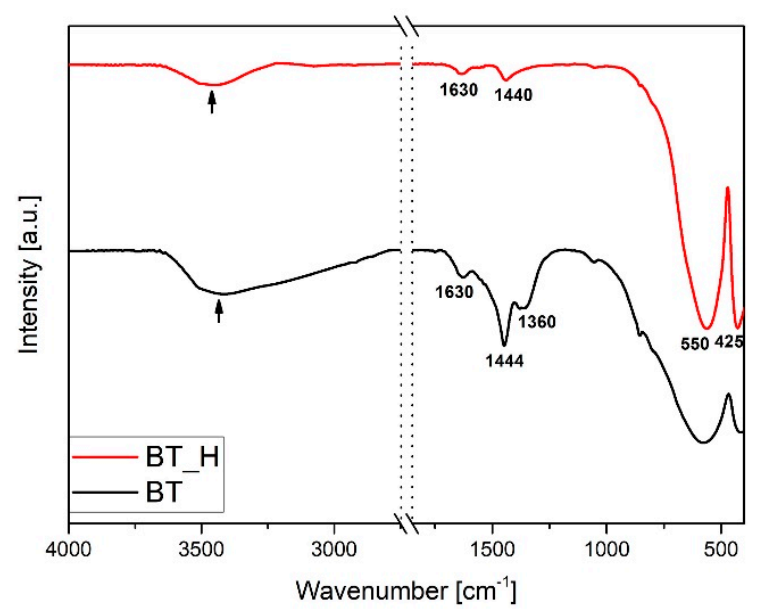

Figure 2. FTIR spectra of powders produced by sol-gel method at ambient pressure (BT) and hydrothermal conditions (BT_H).

In the BT spectrum a complex band is present in the range $1700-1250 \mathrm{~cm}^{-1}$. The main component at $1444 \mathrm{~cm}^{-1}$ [45], due to the normal vibration of carbonate groups, is overlapped to the signals of residual acetates in the range $1550-1300 \mathrm{~cm}^{-1}$ [46-48]. The band at $1630 \mathrm{~cm}^{-1}$ is due to the water scissoring vibration of adsorbed water. In the corresponding $\mathrm{OH}$ stretching band centered at $3500 \mathrm{~cm}^{-1}$, the high wavenumber component is attributable to the BT hydroxyl groups. The intensity of the carbonate signal $\left(1440 \mathrm{~cm}^{-1}\right)$ is strongly reduced in the BT_H spectrum and no evident signals of residual acetates can be appreciated. The FTIR spectra of powders annealed at $900{ }^{\circ} \mathrm{C}$ are reported in Figure 3. The thermal treatment leads to the disappearance of residual organic groups and strong reduction of carbonates in agreement with TGA-DTA results $[40,49]$. It is worth noting that carbonate vibrations also appear in the spectrum of the commercial product, reported in Figure 3 for the sake of comparison. The characteristic titanate signals are narrower in both sol-gel samples with respect to the commercial product. The spectra of annealed nanoparticles are also representative of the doped samples.

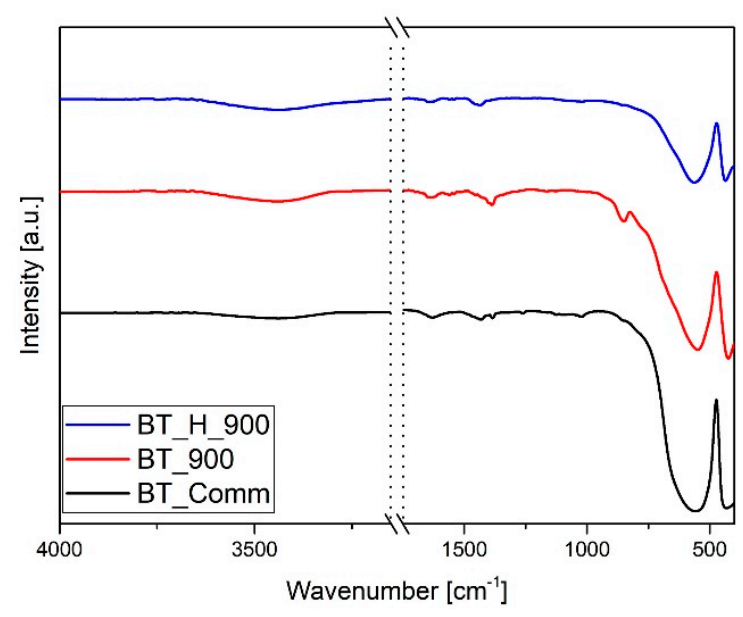

Figure 3. FTIR spectra of BT_comm, BT_900, and BT_H_900.

\subsection{Effect of Hydrothermal Reaction Time}

SEM images on barium titanate powders were obtained to evaluate the size, the distribution, and the morphology of particles. Figure 4 shows the SEM micrographs of commercial particles and sol-gel powders, prepared both at ambient pressure and in hydrothermal conditions. 


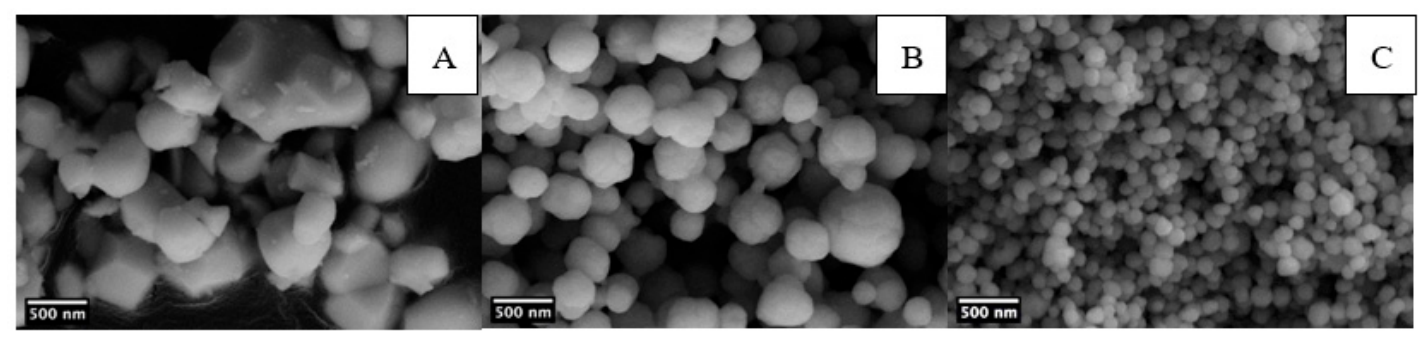

Figure 4. SEM micrographs of BT_comm (A), BT_900 (B), and BT_H_900 (C).

SEM images show that fine powders from synthesis at ambient pressure form through the agglomeration of primary particles [28,35], which is also valid for hydrothermal samples. Table 2 summarizes the results of the particle analysis performed by ImageJ software. Particles obtained by sol-gel synthesis at ambient conditions (BT_900 sample, mean size $376 \mathrm{~nm}$ ) are spherical smaller in size and with narrower distribution with respect to commercial BT particles (BT_comm sample, mean size $496 \mathrm{~nm}$ ), which display less regular morphology. The $2 \mathrm{~h}$ hydrothermal treatment (BT_H_900 sample, mean size $117 \mathrm{~nm}$ ) leads to a relevant decrease in particle dimensions, and even narrower size distribution was obtained as compared with BT_900 sample.

Table 2. Results of the particle size analysis from SEM micrographs.

\begin{tabular}{ccccccc}
\hline & BT_comm & BT_900 & BT_H_900 & BT_H4h_900 & BT_H6h_900 & BT_H8h_900 \\
\hline Mean $(\mathrm{nm})$ & $496 \pm 178$ & $376 \pm 99$ & $117 \pm 27$ & $127 \pm 31$ & $131 \pm 40$ & $162 \pm 56$ \\
\hline
\end{tabular}

The effect of the duration of the hydrothermal processing was studied acquiring the SEM micrographs of BT nanoparticles produced with $2 \mathrm{~h}, 4 \mathrm{~h}, 6 \mathrm{~h}$, and $8 \mathrm{~h}$ reaction time (Figure 5). Increasing the hydrothermal reaction time from $2 \mathrm{~h}$ to $8 \mathrm{~h}$ does not have remarkable effects on the particle size [50]. The mean particle size was found only to slightly increase from 117 to $162 \mathrm{~nm}$ with a corresponding broadening of the size distribution (Table 2). Up to $6 \mathrm{~h}$ reaction time NPs are spherical, whereas the sample obtained after $8 \mathrm{~h}$ hydrothermal treatment presents bigger and more elongated particles, with the appearance of necks. From these results, it appears that a $2 \mathrm{~h}$ hydrothermal treatment is preferable, as it saves time and produces spherical particles with a narrow size distribution compared to higher reaction times.

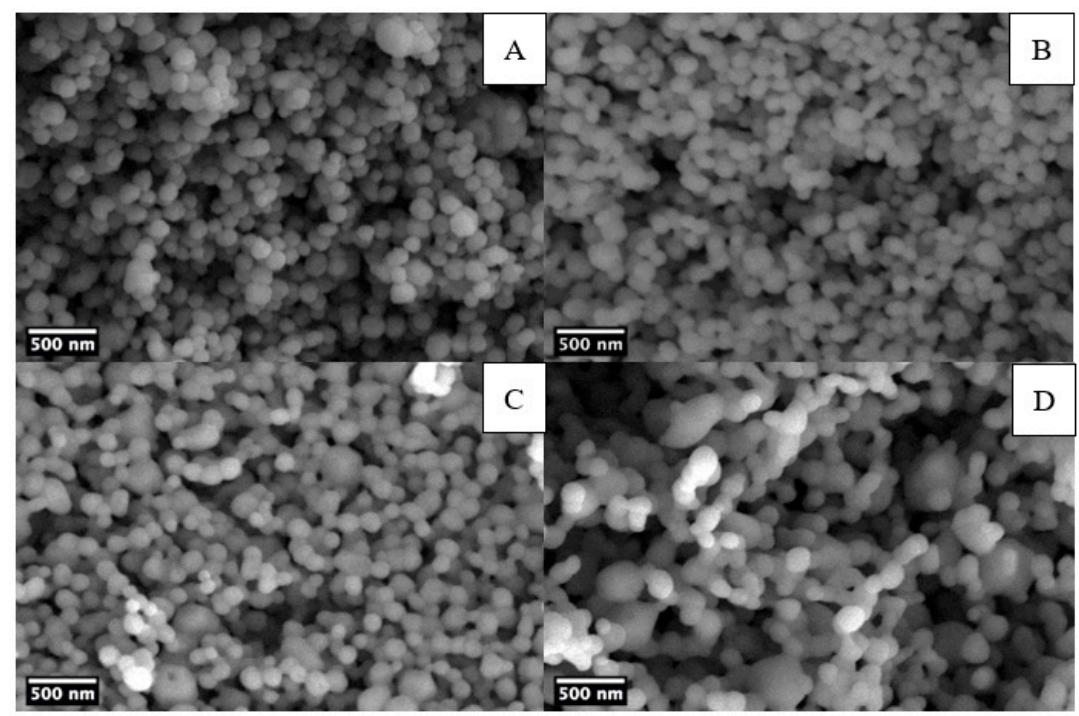

Figure 5. SEM micrographs of BT particles in hydrothermal conditions at different processing times: $2 \mathrm{~h}(\mathrm{~A}), 4 \mathrm{~h}(\mathrm{~B}), 6 \mathrm{~h}(\mathrm{C})$, and $8 \mathrm{~h}(\mathrm{D})$. 
Figure 6 shows the $\mathrm{N}_{2}$ physisorption isotherms of barium titanate produced at both ambient pressure and in hydrothermal conditions $(2 \mathrm{~h})$ and annealed at $900^{\circ} \mathrm{C}$. Powders display type II isotherms [51]. The BET-specific surface area (SSA) values of BT_900 and BT_H_900 samples are, respectively, $2.87 \mathrm{~m}^{2} / \mathrm{g}$ and $5.95 \mathrm{~m}^{2} / \mathrm{g}$, which are consistent with the main contribution of the geometrical surface in dense particles. However, the $\mathrm{BJH}$ model applied to the adsorption curve indicates the presence of some porosity. This porosity has a bimodal behavior with pore diameters ranging from 2 to $10 \mathrm{~nm}$ and from 13 to $90 \mathrm{~nm}$.

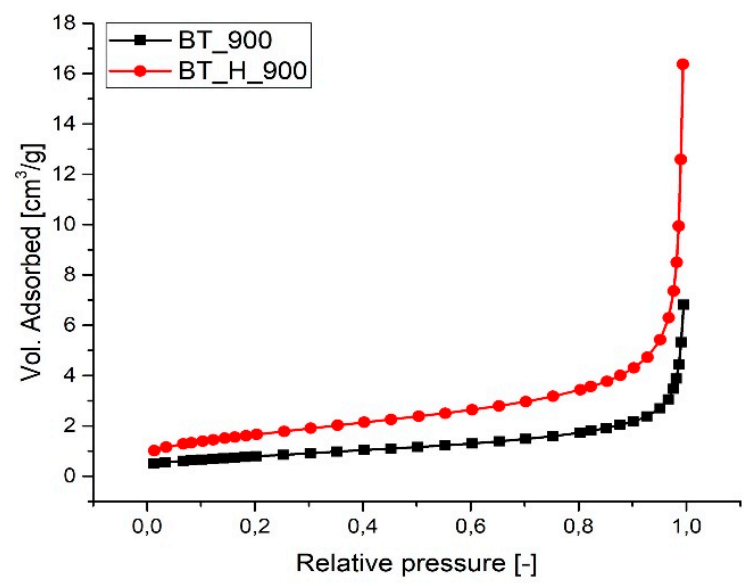

Figure 6. $\mathrm{N}_{2}$ adsorption isotherms of BT_900 and BT_H_900.

Assuming spherical particles, the mean particle size was calculated using the following formula:

$$
\mathrm{D}=6000 /\left(\mathrm{SSA}_{\mathrm{BET}} \times \rho\right)
$$

where $\mathrm{D}$ is the mean diameter (in nm), SSA is the value of the BET specific surface area (in $\mathrm{m}^{2} / \mathrm{g}$ ) and $\rho$ is the density of barium titanate (theoretical, $6.02 \mathrm{~g} / \mathrm{cm}^{3}$ ). Mean diameter was calculated to be equal to $347 \mathrm{~nm}$ for BT_900 and 167 for BT_H_900. These dimensions, within the experimental error, are comparable with those measured from SEM micrographs.

X-ray diffraction patterns (Figure 7) were acquired on both annealed particles and on commercial barium titanate in order to evaluate phase composition, lattice parameters, crystallinity, and crystallite size.

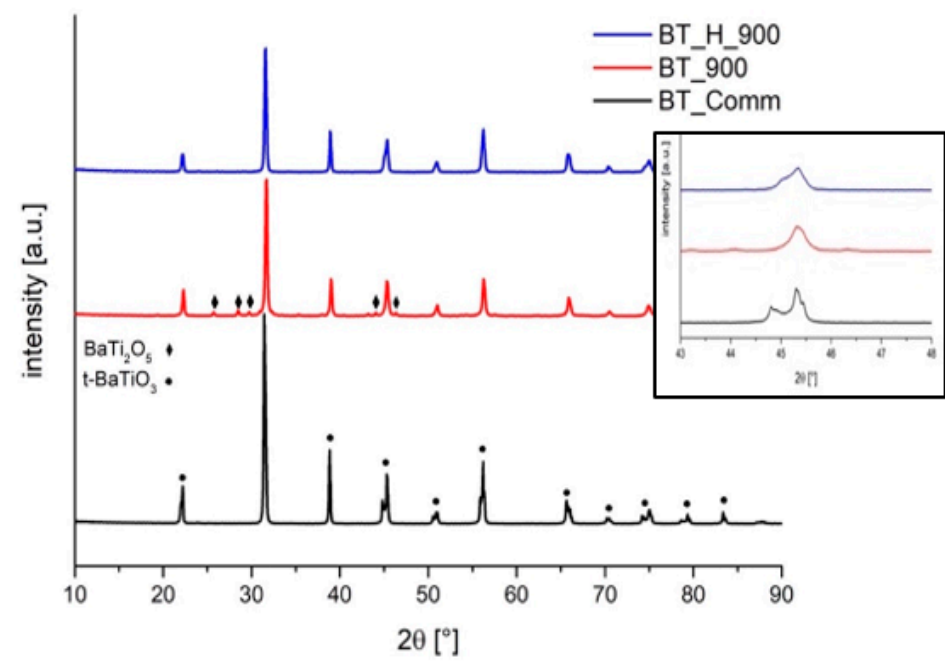

Figure 7. XRD patterns of BT_comm, BT_900, and BT_H_900. The signal at $2 \theta=45^{\circ}$ is shown in the figure inset. 
Barium titanate tetragonal phase (PDF 5-626) is evidenced by the presence of a doublet at $2 \theta=45^{\circ}$ [52,53], whereas the cubic phase (PDF 31-174) is recognized by a single peak at $2 \theta=45^{\circ}$ and the coexistence of the two phases by a main peak combined with a shoulder. As shown in Figure 7, XRD pattern of commercial powders clearly presents a doublet, while annealed powders from sol-gel both at ambient pressure and hydrothermal condition present an intermediate situation, with the main peak and a shoulder (Figure 7, inset), evidence of the coexistence of both tetragonal and cubic phase. No additional phases are found in hydrothermal powders over cubic and tetragonal. On the contrary, BT_900 sample presents traces of metastable $\mathrm{BaTi}_{2} \mathrm{O}_{5}$ oxide (monoclinic PDF 8-368). As explained by Ritter et al. [37], several oxides, such as $\mathrm{BaTi}_{2} \mathrm{O}_{5}, \mathrm{BaTi}_{5} \mathrm{O}_{11}$, and $\mathrm{Ba}_{2} \mathrm{TiO}_{4}$, can form, depending on the $\mathrm{Ba} / \mathrm{Ti}$ ratio, which crystallize at $700{ }^{\circ} \mathrm{C}$ and are quite stable up to $900-1100{ }^{\circ} \mathrm{C}$. The mechanisms behind the formation of these oxides are very complex but it is supposed that both water and acetic acid amount used in the sol synthesis play a role. On the other hand, BT powders produced in hydrothermal conditions are made only by $\mathrm{BaTiO}_{3}$, and tetragonal and cubic phase coexist in all samples produced. In order to evaluate the relative amounts of tetragonal and cubic phase and the lattice parameters, Rietveld analysis was applied to XRD patterns [36,54]. Table 3 shows the calculated relative weight amounts of tetragonal and cubic phase in the undoped annealed samples.

Table 3. Quantitative phase analysis, crystallite size, and lattice parameters of undoped BT powders.

\begin{tabular}{|c|c|c|c|c|c|c|}
\hline Sample & BT_comm & BT_900 & BT_H_900 & BT_H4h_900 & BT_H6h_900 & BT_H8h_900 \\
\hline $\begin{array}{l}\text { Phase } \\
\text { [wt.\%] }\end{array}$ & $\begin{array}{c}\text { Tetra } \\
100\end{array}$ & $\begin{array}{l}\text { Tetra-Other } \\
85(2)-15(2)\end{array}$ & $\begin{array}{l}\text { Tetra-Cubic } \\
75(1)-25(1)\end{array}$ & $\begin{array}{l}\text { Tetra-Cubic } \\
73(3)-27(3)\end{array}$ & $\begin{array}{l}\text { Tetra-Cubic } \\
74(3)-26(3)\end{array}$ & $\begin{array}{l}\text { Tetra-Cubic } \\
78(2)-22(2)\end{array}$ \\
\hline $\begin{array}{c}\text { Crystallite } \\
\text { (std.dev) [nm] }\end{array}$ & $114(1)$ & 46(1)-na & $77(4)-82(14)$ & $75(1)-114(18)$ & 73(3)-92(16) & $75(4)-171(46)$ \\
\hline a [Å] (tetra) & 3.9995 & 4.0105 & 4.0039 & 4.0053 & 4.0049 & 4.0042 \\
\hline c [A] (tetra) & 4.0393 & 4.0239 & 4.0333 & 4.0305 & 4.0318 & 4.0342 \\
\hline $\mathrm{t}=\mathrm{c} / \mathrm{a}($ tetra $)$ & 1.010 & 1.0033 & 1.0074 & 1.0063 & 1.0069 & 1.0075 \\
\hline Rwp [\%] & 15.09 & 12.94 & 18.05 & 20.00 & 16.04 & 15.43 \\
\hline
\end{tabular}

The relative amount of tetragonal phase is about $75 \%$ regardless of the hydrothermal reaction time and this evidence confirms that it is worth to use the shorter hydrothermal treatment $(2 \mathrm{~h})$, considering that it leads also to better results in terms of particles morphology according to SEM observations. Table 3 also presents crystallite size, lattice parameters, and tetragonality calculated for the undoped samples. The commercial powders present crystallites of $114 \mathrm{~nm}$, whereas crystallites of $46 \mathrm{~nm}$ are found for BT_900. The evaluation of the crystallite dimensions of hydrothermal powders is affected by the coexistence of cubic and tetragonal lattices. The fitting of experimental data was performed using the reference powder diffraction files of both tetragonal and cubic crystalline phases. Unfortunately, the overlapping of the characteristic diffraction peaks of the tetragonal and cubic crystalline makes it more difficult to assess the crystallite size for the cubic structure, which is the minority phase, as demonstrated by the higher standard deviation values reported in Table 3. However, the residual weight percentage ( $R w p)$ is sufficiently low to consider reliable the results, which suggests a constant trend in size for the tetragonal phase and an increase for the cubic with the increase of the duration of the hydrothermal treatment. To evaluate the dependence of the results on the structural models, the refinement was also performed using separately the PDF of the tetragonal and cubic structures. The results confirmed for the tetragonal phase crystallite sizes in the range 70-75 $\mathrm{nm}$; smaller crystallites (42-52 $\mathrm{nm}$ ) were calculated for the cubic phase, but these latter results are accompanied by a higher Rwp [\%], strengthening the assumption that the coexistence of phases is the cause of the high error in the assessment of crystallite size of the minor phase. The key parameter to have high piezoelectric performance are: tetragonality, amount of 
tetragonal phase, grain size, domain size, and orientation [55,56]. In accordance with the literature, the highest achievable value of tetragonality $t$ is 1.010 [57] through the solid-state route. Table 3 shows the lattice parameters of all samples. Powders from hydrothermal synthesis display much higher values of tetragonality (1.006-1.007) with respect to ambient pressure sample (1.003); their value is not so far from the maximum, even if treated at relatively low temperatures $\left(900{ }^{\circ} \mathrm{C}\right.$ with respect to $1100-1400{ }^{\circ} \mathrm{C}$ typical of solid-state reactions). The hydrothermal reaction time seems to have little effect on lattice parameters and, consequently, on tetragonality, as shown in Figure 8.

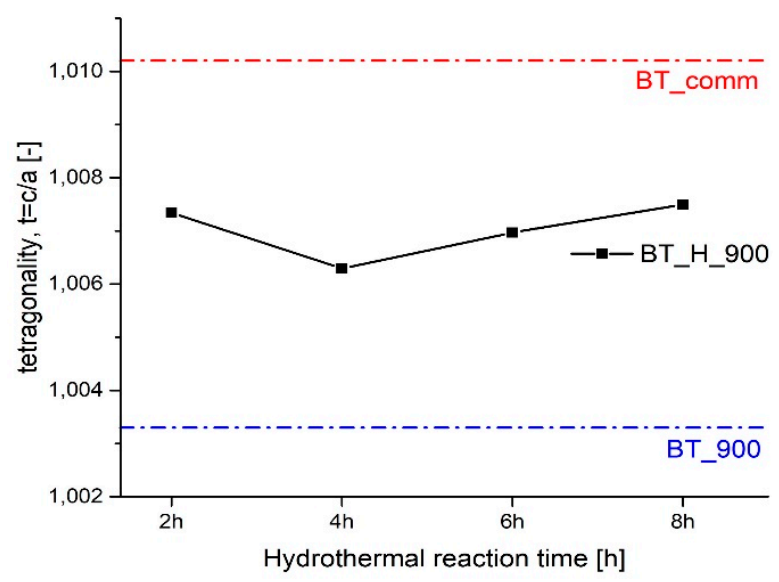

Figure 8. Trend of tetragonality as a function of the hydrothermal reaction time.

Raman spectroscopy is a highly sensitive spectroscopic technique to probe the local structure of atoms in materials; hence, Raman studies have been carried out to investigate the structure as a function of the conditions employed to synthetize the $\mathrm{BaTiO}_{3}$ nanoparticles. Figure 9 shows Raman spectra acquired on the samples labeled BT_comm, BT_900, and BT_H_900. Analyzing the spectra reported in Figure 9, it is possible to distinguish the typical Raman-active modes for tetragonal $\mathrm{BaTiO}_{3}: 4 \mathrm{E}(\mathrm{TO}+\mathrm{LO})+3 \mathrm{~A}_{1}(\mathrm{TO}+\mathrm{LO})+\mathrm{B}_{1}(\mathrm{TO}$ $+\mathrm{LO})$. The phonon modes corresponding to Raman bands are assigned as proposed by Dixit et al. [58]. Moreover, the observed anti-resonance effect at $183 \mathrm{~cm}^{-1}$ as an interference feature, is attributed by Scalabrin et al. to a coupling between the sharp $\mathrm{A}_{1}\left(\mathrm{TO}_{1}\right)$ and broad $\mathrm{A}_{1}\left(\mathrm{TO}_{2}\right)$ modes [59]. Furthermore, it is well known that the $\mathrm{BaTiO}_{3}$ tetragonal phase presents Raman scattering bands at around 250,520, and $720 \mathrm{~cm}^{-1}$ and a sharp peak at around $306 \mathrm{~cm}^{-1}$ [60].

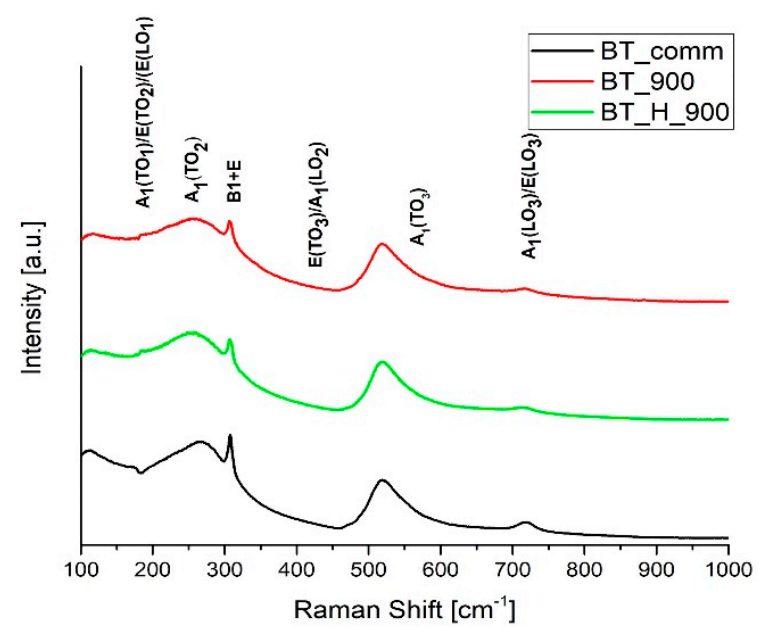

Figure 9. Raman spectra of $\mathrm{BaTiO}_{3}$ samples: BT_comm (black line), BT_900 (red line), and BT_H_900 (green line). 
According to these assignments, the Raman spectra confirm that the BT samples have a tetragonal structure, in agreement with XRD results. Furthermore, according to the intensity of the signal at $306 \mathrm{~cm}^{-1}$, higher tetragonality of commercial powders is confirmed, as also shown from the XRD analysis.

\subsection{Effect of Doping}

The effect of doping on the powder microstructural features was also analyzed. Table 4 summarizes the calculated molar percentages of $\mathrm{Ba}$ and dopant cations for the undoped and the doped samples and reports the Ba/Ti molar ratio, obtained from ICP-OES measurements. According to the elemental analysis, both undoped and doped samples are barium deficient even if a Ba/Ti molar ratio 1.1 was used in the synthesis. This is in accordance with the literature, which points out the difficulty of obtaining stoichiometric $\mathrm{BaTiO}_{3}$ powders through chemical syntheses performed in strongly basic conditions [61-64]. Elemental analysis (Table 4) confirmed the presence of $\mathrm{Ca}, \mathrm{Na}$, and $\mathrm{Bi}$ dopants in the samples, but their quantity is lower with respect to the nominal one, meaning that the doping effectiveness is lower than expected. In addition, $\mathrm{K}$ is detected in all samples as a consequence of the use of $\mathrm{KOH}$ in the synthesis. $\mathrm{K}$ traces are found when doping with a divalent ion or a combination of monovalent and trivalent ions; on the contrary, high $\mathrm{K}$ content is found in $\mathrm{Na}$ - and Bi-doped samples. Moreover, sodium is also detected in undoped and Ca- and Bi-doped samples, due to its presence in $\mathrm{KOH}$ starting solution. According to the literature, $\mathrm{K}^{+}, \mathrm{Na}^{+}, \mathrm{Ca}^{2+}$, and $\mathrm{Bi}^{3+}$ ions substitute $\mathrm{Ba}^{2+}$ in the A-site of the perovskitic structure, mainly because of the ionic radius dimension [65-71]. According to the values reported in Table 4, the $\mathrm{Ba} / \mathrm{Ti}$ ratio decreases in the doped samples with respect to undoped BT. This is a direct consequence of the Ba substitution by the dopant cations. In details, $\mathrm{Ca}^{2+}$ effectively substitute $\mathrm{Ba}^{2+}$, due to the maintenance of the charge balance, thus leading to the lowest $\mathrm{Ba} / \mathrm{Ti}$ ratio. In the case of the Na-doped sample, the amount of $\mathrm{Na}$ is limited but a large doping contribution comes from $\mathrm{K}$ probably due to the ionic radius that is closer to that of Ba. In order to keep the charge balance, the substitution of divalent cations with monovalent cations in A-site leads to a significant decrease of $\mathrm{Ba} / \mathrm{Ti}$ ratio. The case of the Bi-doped sample deserves two comments. Taking into consideration the charge balance, the amount of $\mathrm{Bi}^{3+}$ should be necessary limited, but this sample also displays a large amount of potassium, thus justifying the contained variation in Ba/Ti ratio. Similar considerations can be made for BT_H_NaBi_900 sample. Both charge balance and dopants size could affect the different amount of $\mathrm{K}$ detected in the samples. As reported above, the charge balance should play a crucial role but dopants size could also affect the extent of substitution, since this has a relevant effect on unit cell deformation. However, the K amount in the Bi-doped sample is surprisingly high and will be a matter of future investigation.

Table 4. Experimental molar composition of $\mathrm{BaTiO}_{3}$-doped samples from ICP-OES results.

\begin{tabular}{cccccccc}
\hline & Ba/Ti mol Ratio & mol\% Ba & $\mathbf{m o l} \% \mathbf{~ T i}$ & $\mathbf{m o l ~ K} \%$ & $\mathbf{m o l ~ N a} \%$ & $\mathbf{m o l ~ C a} \%$ & $\mathbf{m o l ~ B i \%}$ \\
\hline BT_H_900 & 0.86 & 45.1 & 52.2 & 2.6 & 0.1 & - & - \\
BT_H_Na_900 & 0.76 & 40.0 & 52.6 & 5.5 & 1.9 & - & - \\
BT_H_Ca_900 & 0.74 & 38.6 & 52.1 & 0.2 & 1.7 & - \\
BT_H_Bi_900 & 0.82 & 37.9 & 46.3 & 10.1 & 3.4 & - & 2.3 \\
BT_H_NaBi_900 & 0.81 & 41.7 & 51.6 & 0.3 & 2.0 & - & 4.4 \\
\hline
\end{tabular}

Figure 10 shows the SEM micrographs of the doped samples. It can be seen that particles are spherical and quite homogeneous. Table 5 summarizes the results of particle size analysis performed with the software ImageJ. Particles have a similar dimension, ranging from 134 to $149 \mathrm{~nm}$, regardless of the nature of doping. However, if compared with the BT_H_900, the doped samples present a slightly bigger mean size and broader distribution (higher standard deviation). 


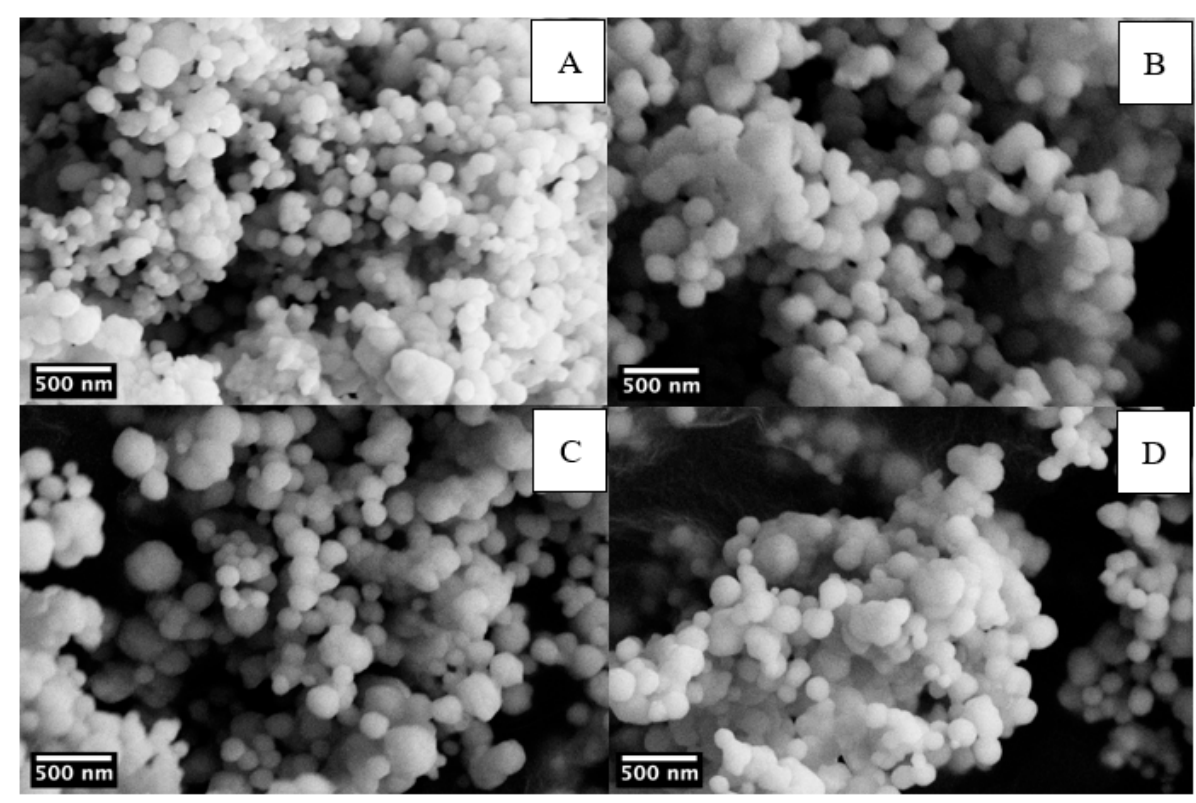

Figure 10. SEM micrographs of BT doped particles: BT_H_Na_900 (A), BT_H_Ca_900 (B), BT_H_Bi_900 (C), and BT_H_NaBi_900 (D).

Table 5. Results of the particle size analysis from SEM micrographs for the doped samples.

\begin{tabular}{ccccc}
\hline & BT_H_Na_900 & BT_H_Ca_900 & BT_H_Bi_900 & BT_H_NaBi_900 \\
\hline Mean (nm) & $134 \pm 37$ & $149 \pm 33$ & $146 \pm 39$ & $141 \pm 37$ \\
\hline
\end{tabular}

XRD patterns of the doped samples confirm the presence of the $\mathrm{BaTiO}_{3}$ phase in all samples, as shown in Figure 11. Generally, no additional phases are found. Only in the case of the Bi-doped sample, as also reported by Zhou et al. [68], traces of $\mathrm{Bi}_{2} \mathrm{Ti}_{2} \mathrm{O}_{4}$ (PDF 32-0118) are detected (<0.5 wt.\% from Rietveld analysis). Table 6 summarizes the results of the XRD pattern analysis of the doped BT powders. It is worth to note that all the simulations made by MAUD software present a reliable goodness of fitting and Rwp (\%). The Ca addition does not affect both relative amount of tetragonal phase and tetragonality, which appear almost unchanged with respect to the values calculated for BT_H_900 sample. The substitution of $\mathrm{Ba}^{2+}$ with a smaller divalent cation leads to a decrease of both unit cell parameters, therefore keeping the $t$ value (1.0070) almost unchanged. According to the literature [70], the presence of heterovalent ions leads to a decrease of the tetragonality parameter, as observable in Table 6. In case of Na-doping, the quantitative analysis evidenced that lower amount of tetragonal phase was formed after annealing. On the other hand, Bi-doping and the combined NaBi-doping have an opposite effect: when both bismuth and sodium are added, the relative amount of tetragonal phase is higher than when bismuth is standalone. For both samples, a decrease in tetragonality values is observed due to a more pronounced shortening of c length. Finally, concerning the crystallite size dimension, it can be observed that dopant addition leads to variation depending on the nature of the element. Calcium doping produces an increase in size both for tetragonal and cubic phases, whereas $\mathrm{Bi}$ and $\mathrm{Bi} / \mathrm{Na}$ addition leads to decreasing the crystallite dimension. Additionally, here, the standard deviation associated to the cubic phase is higher with respect to the one associated with the main tetragonal phase. 


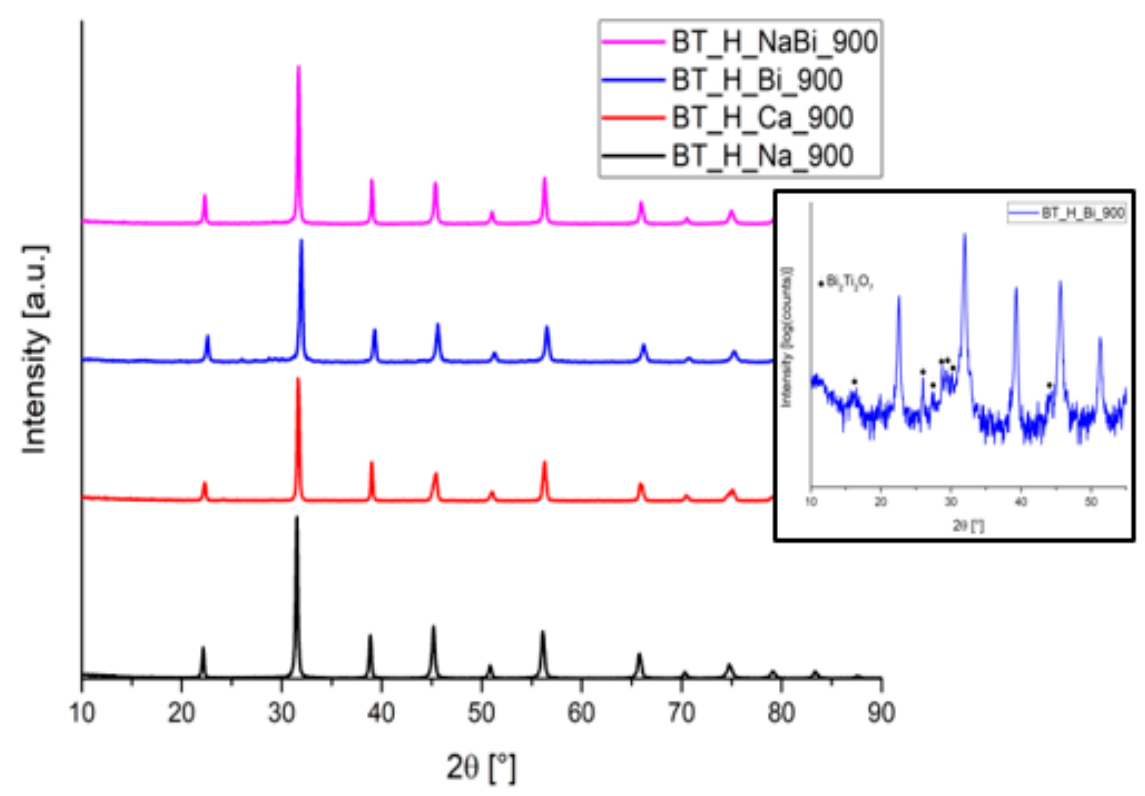

Figure 11. XRD patterns of doped $\mathrm{BaTiO}_{3}$ samples: BT_H_Na_900 (black line), BT_H_Ca_900 (red line), BT_H_Bi_900 (blue line), and BT_H_NaBi_900 (pink line). Inset: BT_H_Bi_900 pattern shown in log scale to highlight the presence of secondary phase traces.

Table 6. Quantitative phase analysis, crystallite size, and lattice parameters of doped BT powders.

\begin{tabular}{|c|c|c|c|c|c|}
\hline Sample & BT_H_900 & BT_H_Na_900 & BT_H_Ca_900 & BT_H_Bi_900 & BT_H_NaBi_900 \\
\hline Phase & Tetra-Cubic & Tetra-Cubic & Tetra-Cubic & Tetra-Cubic & Tetra-Cubic \\
\hline [wt.\%] & $75(1)-25(1)$ & $56(2)-44(2)$ & $76(2)-24(2)$ & $84(4)-16(3)$ & $90(1)-10(1)$ \\
\hline $\begin{array}{c}\text { Crystallite } \\
\text { (std.dev) [nm] }\end{array}$ & $77(4)-82(14)$ & $27(1)-57(1)$ & $62(1)-112(30)$ & $47(2)-12(1)$ & $60(1)-7(1)$ \\
\hline a [^] (tetra) & 4.0039 & 4.0101 & 4.0007 & 4.0020 & 4.0101 \\
\hline c $[\AA]$ (tetra) & 4.0333 & 4.0331 & 4.0286 & 4.0155 & 4.0221 \\
\hline $\mathrm{t}=\mathrm{c} / \mathrm{a}($ tetra $)$ & 1.0074 & 1.0057 & 1.0070 & 1.0034 & 1.0030 \\
\hline Rwp [\%] & 18.05 & 17.00 & 21.49 & 14.89 & 17.89 \\
\hline
\end{tabular}

A complementary study, using the Raman Spectroscopy technique, has been carried out to probe the effect of doping $\left(\mathrm{Na}^{+}, \mathrm{Ca}^{2+}\right.$ and $\left.\mathrm{Bi}^{3+}\right)$ on the $\mathrm{BaTiO}_{3}$ structure. Figure 12 shows the Raman spectra of cation-doped $\mathrm{BaTiO}_{3}$ : (a) in sample BT_H_Ca_900, it is not possible to appreciate any significant variation between reference and the $\mathrm{Ca}^{2+}$ doped sample, suggesting that in this case, the Ca addition does not modify the structural features of the nanoparticles, in agreement with what was established by the XRD analysis, (b) in the sample with $\mathrm{Na}^{+}$doping (green line), a decrease of the intensity peak is evident at $306 \mathrm{~cm}^{-1}$ related to the $\mathrm{B}+\mathrm{E}$ mode, indicating a lower amount of tetragonal phase with respect to the blank one, as evidenced by Hayashi et al. [60] and confirmed by XRD quantitative analysis; (c) finally, for both BT_H_Bi_900 and BT_H_NaBi_900 samples, the $\mathrm{Bi}^{3+}$ doping produces a modification in the structure with a shift towards higher wavenumbers of the modes $\mathrm{A}_{1}$ (TO) at 250-270 $\mathrm{cm}^{-1}$, and $\mathrm{A}_{1}, \mathrm{E}(\mathrm{TO})$ at $510-520 \mathrm{~cm}^{-1}$ with respect to the undoped $\mathrm{BaTiO}_{3}$, in agreement to what was already reported by Strathdee et al. [72]. 


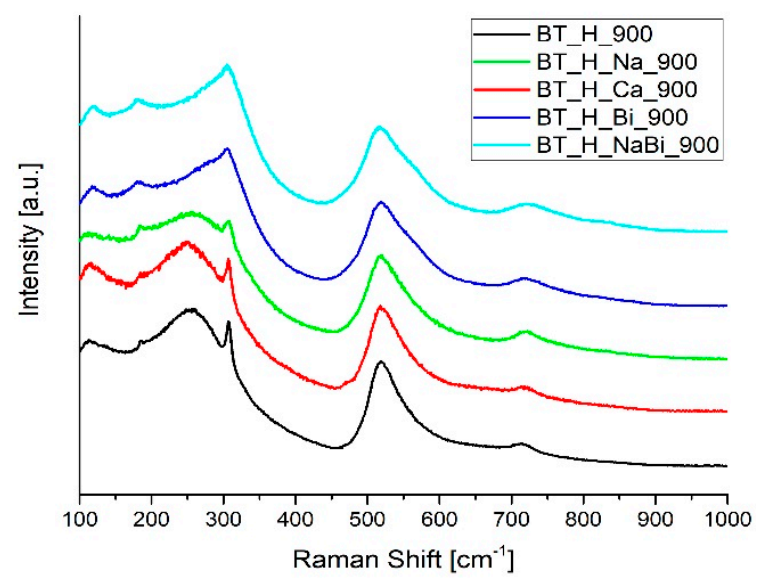

Figure 12. Raman spectra of cation-doped $\mathrm{BaTiO}_{3}$ systems: (black line) undoped sample, (red line) BT_H_Ca_900 sample, (green line) BT_H_Na_900, (blue line) BT_H_Bi_900, (light blue line) BT_H_NaBi_900.

\section{Conclusions}

In conclusion, $\mathrm{BaTiO}_{3}$ nanoparticles were produced both by traditional sol-gel synthesis and under hydrothermal conditions. The hydrothermal treatment presented some evident advantages over the sol-gel route at ambient pressure. Nanoparticles from hydrothermal synthesis were spherical, more homogeneous, and with narrower size distribution with respect to classic solid-state route or traditional sol-gel synthesis. Furthermore, it was demonstrated that a longer duration of the hydrothermal process causes a broadening in particle size distribution combined with the appearance of some necks among particles. FTIR showed the presence of organic residuals in powders prepared by sol-gel synthesis at ambient pressure, which were removed after annealing at $900{ }^{\circ} \mathrm{C}$. XRD analysis indicated a high amount of tetragonal phase and high values of tetragonality, even if they were annealed at a relatively low temperature $\left(900^{\circ} \mathrm{C}\right)$ with respect to the conventional production method. These findings were also confirmed by Raman spectroscopy. The hydrothermal reaction time $(2-8 \mathrm{~h})$ was demonstrated to have almost no effect on the amount of tetragonal phase and on tetragonality. Considering also the morphological analysis performed through SEM observation, these results led to the conclusion that a $2 \mathrm{~h}$ hydrothermal process is time-saving and produces spherical particles with narrower size distribution and high value of tetragonality compared to higher reaction time.

Finally, NPs doping was performed with $\mathrm{Na}, \mathrm{Ca}$, and $\mathrm{Bi}$ and the effect of dopant on microstructure and cubic-to-tetragonal phase transformation was evaluated. In particular, the addition of both $\mathrm{Na}$ and $\mathrm{Bi}$ ions improved the transformation and led to decreasing crystallite dimensions, while Ca-doping did not result in appreciable variations of BT powder properties. Tetragonality was found to decrease in all doped samples, in agreement with the literature, even if Ca doping did not alter this value significantly. The effect of dopants on the microstructural properties of barium titanate depends both on charge and ionic radius of doping ions. The balance of unit cell deformation and charge imbalance seems to rule the dopant concentration. Due to the sample preparation procedure, potassium was detected in all samples in different amounts, depending on the nature of the dopant element. Furthermore, the particle dimension for doped samples was found to be slightly higher with respect to the undoped sample (BT_H_900).

Author Contributions: Conceptualization, N.Z. and S.D.; methodology, N.Z., S.D., R.C. and A.C.; validation, N.Z., A.P., M.F., S.D., R.C. and A.C.; formal analysis, N.Z.; investigation, N.Z.; resources, S.D., R.C., A.P., M.F. and A.C.; data curation, N.Z.; writing-original draft preparation, N.Z.; writingreview and editing, S.D., A.P., M.F., R.C. and A.C.; supervision, S.D., A.P. and M.F.; visualization, N.Z.; supervision, S.D.; funding acquisition, A.P., M.F., and S.D. All authors have read and agreed to the published version of the manuscript. 
Funding: This research received no external funding.

Institutional Review Board Statement: Not applicable.

Informed Consent Statement: Not applicable.

Data Availability Statement: The data presented in this study are available on request from the corresponding author.

Acknowledgments: Lorenzo Moschini (Biotech-DII, University of Trento) is warmly acknowledged for SEM experimental analysis.

Conflicts of Interest: The authors declare no conflict of interest.

\section{References}

1. Chinya, I.; Sasmal, A.; Pal, A.; Sen, S. Flexible Piezoelectric Energy Harvesters Using Different Architectures of Ferrite Based Nanocomposites. CrystEngComm 2019, 21, 3478-3488. [CrossRef]

2. Zhang, Y.; Jeong, C.K.; Wang, J.; Sun, H.; Li, F.; Zhang, G.; Chen, L.Q.; Zhang, S.; Chen, W.; Wang, Q. Flexible Energy Harvesting Polymer Composites Based on Biofibril-Templated 3-Dimensional Interconnected Piezoceramics. Nano Energy 2018, 50 , 35-42. [CrossRef]

3. Xie, M.; Zhang, Y.; Kraśny, M.J.; Bowen, C.; Khanbareh, H.; Gathercole, N. Flexible and Active Self-Powered Pressure, Shear Sensors Based on Freeze Casting Ceramic-Polymer Composites. Energy Environ. Sci. 2018, 11, 2919-2927. [CrossRef] [PubMed]

4. Smith, G.L.; Pulskamp, J.S.; Sanchez, L.M.; Potrepka, D.M.; Proie, R.M.; Ivanov, T.G.; Rudy, R.Q.; Nothwang, W.D.; Bedair, S.S.; Meyer, C.D.; et al. PZT-Based Piezoelectric MEMS Technology. J. Am. Ceram. Soc. 2012, 95, 1777-1792. [CrossRef]

5. Furukawa, T.; Ishida, K.; Fukada, E. Piezoelectric Properties in the Composite Systems of Polymers and PZT Ceramics. J. Appl. Phys. 1979, 50, 4904-4912. [CrossRef]

6. Tressler, J.F.; Alkoy, S.; Newnham, R.E. Piezoelectric Sensors and Sensor Materials. J. Electroceramics 1998, 2, 257-272. [CrossRef]

7. Guo, R.; Cross, L.E.; Park, S.-E.; Noheda, B.; Cox, D.E.; Shirane, G. Origin of the High Piezoelectric Response in $\mathrm{PbZr}_{1-\mathrm{x}} \mathrm{Ti}_{\mathrm{x}} \mathrm{O}_{3}$. Phys. Rev. Lett. 2000, 84, 5423-5426. [CrossRef]

8. Panda, P.K.; Sahoo, B. PZT to Lead Free Piezo Ceramics: A Review. Ferroelectrics 2015, 474, 128-143. [CrossRef]

9. Shrout, T.R.; Zhang, S.J. Lead-Free Piezoelectric Ceramics: Alternatives for PZT? J. Electroceramics 2007, 19, 111-124. [CrossRef]

10. Nath, R.; Zhong, S.; Alpay, S.P.; Huey, B.D.; Cole, M.W. Enhanced Piezoelectric Response from Barium Strontium Titanate Multilayer Films. Appl. Phys. Lett. 2008, 92, 012916. [CrossRef]

11. Xu, K.; Li, J.; Lv, X.; Wu, J.; Zhang, X.; Xiao, D.; Zhu, J. Superior Piezoelectric Properties in Potassium-Sodium Niobate Lead-Free Ceramics. Adv. Mater. 2016, 28, 8519-8523. [CrossRef] [PubMed]

12. Demartin Maeder, M.; Damjanovic, D.; Setter, N. Lead Free Piezoelectric Materials. J. Electroceramics 2004, 13, 385-392. [CrossRef]

13. Vijatović, M.M.; Bobić, J.D.; Stojanović, B.D. History and Challenges of Barium Titanate: Part II. Sci. Sinter. 2008, 40, 235-244. [CrossRef]

14. Johnsson, M.; Lemmens, P. Crystallography and Chemistry of Perovskites. In Handbook of Magnetism and Advanced Magnetic Materials; Kronmuller, H., Parkin, S., Coey, J.D.M., Inoue, A., Eds.; John Wiley \& Sons, Ltd.: Hoboken, NJ, USA, 2007 ; Volume 4.

15. Sharma, V.; Pilania, G.; Rossetti, G.A.; Slenes, K.; Ramprasad, R. Comprehensive Examination of Dopants and Defects in BaTiO 3 from First Principles. Phys. Rev. B 2013, 87, 134109. [CrossRef]

16. Gomes, M.A.; Lima, Á.S.; Eguiluz, K.I.B.; Salazar-Banda, G.R. Wet Chemical Synthesis of Rare Earth-Doped Barium Titanate Nanoparticles. J. Mater. Sci. 2016, 51, 4709-4727. [CrossRef]

17. Ghosez, P.; Gonze, X.; Lambin, P.; Michenaud, J.-P. Born Effective Charges of Barium Titanate: Band-by-Band Decomposition and Sensitivity to Structural Features. Phys. Rev. B 1995, 51, 6765-6768. [CrossRef]

18. Chávez, E.; Fuentes, S.; Zarate, R.A.; Padilla-Campos, L. Structural Analysis of Nanocrystalline BaTiO 3 . J. Mol. Struct. 2010, 984, 131-136. [CrossRef]

19. Sundar, U.; Lao, Z.; Cook-Chennault, K. Enhanced Dielectric Permittivity of Optimized Surface Modified of Barium Titanate Nanocomposites. Polymers 2020, 12, 827. [CrossRef]

20. Iijima, M.; Sato, N.; Wuled Lenggoro, I.; Kamiya, H. Surface Modification of $\mathrm{BaTiO}_{3}$ Particles by Silane Coupling Agents in Different Solvents and Their Effect on Dielectric Properties of $\mathrm{BaTiO}_{3} /$ Epoxy Composites. Colloid Surf. A Physicochem. Eng. Asp. 2009, 352, 88-93. [CrossRef]

21. Sundar, U.; Lao, Z.; Cook-Chennault, K. Investigation of Piezoelectricity and Resistivity of Surface Modified Barium Titanate Nanocomposites. Polymers 2019, 11, 2123. [CrossRef] [PubMed]

22. Guo, C.; Fuji, M. Effect of Silicone Coupling Agent on Dielectric Properties of Barium Titanate/Silicone Elastomer Composites. Adv. Powder Tech. 2016, 27, 1162-1172. [CrossRef]

23. Cheung, M.C.; Chan, H.L.W.; Choy, C.L. Study on Barium Titanate Ceramics Prepared by Various Methods. J. Mater. Sci. 2001, 36, 381-387. [CrossRef]

24. Stojanovic, B.D.; Simoes, A.Z.; Paiva-Santos, C.O.; Jovalekic, C.; Mitic, V.V.; Varela, J.A. Mechanochemical Synthesis of Barium Titanate. J. Eur. Ceram. Soc. 2005, 25, 1985-1989. [CrossRef] 
25. Akilarasan, M.; Tamilalagan, E.; Chen, S.-M.; Maheshwaran, S.; Chen, T.-W.; Al-Mohaimeed, A.M.; Al-Onazi, W.A.; Soliman Elshikh, M. An Eco-Friendly Low-Temperature Synthetic Approach towards Micro-Pebble-Structured GO@SrTiO $3 \mathrm{Nanocompos}^{-}$ ites for the Detection of 2,4,6-Trichlorophenol in Environmental Samples. Microchim. Acta 2021, 188, 72. [CrossRef]

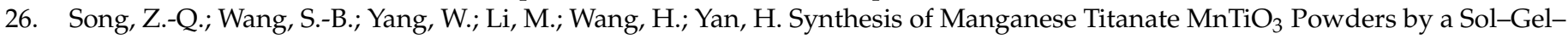
Hydrothermal Method. Mater. Sci. Eng. B 2004, 113, 121-124. [CrossRef]

27. Magnone, E.; Kim, J.R.; Park, J.H. The Effect of the Hydrothermal Synthesis Variables on Barium Titanate Powders. Ceram. Int. 2016, 42, 10030-10036. [CrossRef]

28. Ávila, H.A.; Ramajo, L.A.; Reboredo, M.M.; Castro, M.S.; Parra, R. Hydrothermal Synthesis of BaTiO ${ }_{3}$ from Different Ti-Precursors and Microstructural and Electrical Properties of Sintered Samples with Submicrometric Grain Size. Ceram. Int. 2011, 37, 2383-2390. [CrossRef]

29. Wu, M.; Long, J.; Wang, G.; Huang, A.; Luo, Y. Hydrothermal Synthesis of Tetragonal Barium Titanate from Barium Hydroxide and Titanium Dioxide under Moderate Conditions. J. Am. Ceram. Soc. 1999, 82, 3254-3256. [CrossRef]

30. Xu, H.; Gao, L.; Guo, J. Hydrothermal Synthesis of Tetragonal Barium Titanate from Barium Chloride and Titanium Tetrachloride under Moderate Conditions. J. Am. Ceram. Soc. 2002, 85, 727-729. [CrossRef]

31. Lee, S.K.; Choi, G.J.; Hwang, U.Y.; Koo, K.K.; Park, T.J. Effect of Molar Ratio of KOH to Ti-Isopropoxide on the Formation of BaTiO3 Powders by Hydrothermal Method. Mater. Lett. 2003, 57, 2201-2207. [CrossRef]

32. Yoon, S.; Baik, S.; Kim, M.G.; Shin, N. Formation Mechanisms of Tetragonal Barium Titanate Nanoparticles in Alkoxide-Hydroxide Sol-Precipitation Synthesis. J. Am. Ceram. Soc. 2006, 89, 1816-1821. [CrossRef]

33. Schubert, U. Chemical Modification of Titanium Alkoxides for Sol-Gel Processing. J. Mater. Chem. 2005, 15, 3701-3715. [CrossRef]

34. Hwang, U.Y.; Park, H.S.; Koo, K.K. Behavior of Barium Acetate and Titanium Isopropoxide during the Formation of Crystalline Barium Titanate. Ind. Eng. Chem. Res. 2004, 43, 728-734. [CrossRef]

35. Hwang, U.-Y.; Park, H.-S.; Koo, K.-K. Low-Temperature Synthesis of Fully Crystallized Spherical BaTiO 3 Particles by the Gel-Sol Method. J. Am. Ceram. Soc. 2004, 87, 2168-2174. [CrossRef]

36. Lutterotti, L. Maud: A Rietveld Analysis Program Designed for the Internet and Experiment Integration. Acta Crystallogr. Sect. A Found. Crystallogr. 2000, 56, s54. [CrossRef]

37. Ritter, J.J.; Roth, R.S.; Blendell, J.E. Alkoxide Precursor Synthesis and Characterization of Phases in the Barium-Titanium Oxide System. J. Am. Ceram. Soc. 1986, 69, 155-162. [CrossRef]

38. Chu, J.P.; Chang, C.W.; Mahalingam, T.; Lin, C.C.; Wang, S.F. Effects of Nb Doping on Properties of Barium Titanate Thin Films. J. Mater. Sci. Lett. 2003, 22, 1269-1273. [CrossRef]

39. Frey, M.H.; Payne, D.A. Grain-Size Effect on Structure and Phase Transformations for Barium Titanate. Phys. Rev. B 1996, 54, 3158-3168. [CrossRef]

40. Ashiri, R. Detailed FT-IR Spectroscopy Characterization and Thermal Analysis of Synthesis of Barium Titanate Nanoscale Particles through a Newly Developed Process. Vib. Spectrosc. 2013, 66, 24-29. [CrossRef]

41. Xing, X.; Deng, J.; Chen, J.; Liu, G. Phase Evolution of Barium Titanate from Alkoxide Gel-Derived Precursor. J. Alloys Compd. 2004, 384, 312-317. [CrossRef]

42. Pfaff, G. Sol-Gel Synthesis of Barium Titanate Powders of Various Compositions. J. Mater. Chem. 1992, 2, 591-594. [CrossRef]

43. Vinothini, V.; Singh, P.; Balasubramanian, M. Synthesis of Barium Titanate Nanopowder Using Polymeric Precursor Method. Ceram. Int. 2006, 32, 99-103. [CrossRef]

44. Last, J.T. Infrared-Absorption Studies on Barium Titanate and Related Materials. Phys. Rev. 1957, 105, 1740-1750. [CrossRef]

45. Shahid, T.; Arfan, M.; Zeb, A.; Bibi, T.; Khan, T.M. Preparation and Physical Properties of Functional Barium Carbonate Nanostructures by a Facile Composite-Hydroxide-Mediated Route. Nanomater. Nanotechnol. 2018, 8, 1-8. [CrossRef]

46. Zheng, C.-C.; Cui, B.; You, Q.-M.; Chang, Z.-G. Characterization of $\mathrm{BaTiO}_{3}$ Powders and Ceramics Prepared Using the Sol-Gel Process, with Triton X-100 Used as a Surfactant. In Proceedings of the 7th National Conference on Functional Materials and Applications, Changsha, China, 15-18 October 2010; Scientific Research Publishing: Changsha, China, 2010; pp. 341-346.

47. Parra, R.; Góes, M.S.; Castro, M.S.; Longos, E.; Bueno, P.R.; Varela, J.A. Reaction Pathway to the Synthesis of Anatase via the Chemical Modification of Titanium Isopropoxide with Acetic Acid. Chem. Mater. 2008, 20, 143-150. [CrossRef]

48. Socrates, G. Infrared and Raman Characteristic Group Frequencies; John Wiley \& Sons, Ltd.: Chichester, UK, 2001 ; pp. 115-134.

49. Tangwiwat, S.; Milne, S.J. Barium Titanate Sols Prepared by a Diol-Based Sol-Gel Route. J. Non Cryst. Solids 2005, 351, 976-980. [CrossRef]

50. Wang, W.; Cao, L.; Liu, W.; Su, G.; Zhang, W. Low-Temperature Synthesis of BaTiO3 Powders by the Sol-Gel-Hydrothermal Method. Ceram. Int. 2013, 39, 7127-7134. [CrossRef]

51. Thommes, M.; Kaneko, K.; Neimark, A.V.; Olivier, J.P.; Rodriguez-Reinoso, F.; Rouquerol, J.; Sing, K.S.W. Physisorption of Gases, with Special Reference to the Evaluation of Surface Area and Pore Size Distribution (IUPAC Technical Report). Pure Appl. Chem. 2015, 87, 1051-1069. [CrossRef]

52. Alkathy, M.S.; Hezam, A.; Manoja, K.S.D.; Wang, J.; Cheng, C.; Byrappa, K.; Raju, K.C.J. Effect of Sintering Temperature on Structural, Electrical, and Ferroelectric Properties of Lanthanum and Sodium Co-Substituted Barium Titanate Ceramics. J. Alloys Compd. 2018, 762, 49-61. [CrossRef]

53. Yoon, D.-H. Ceramic Processing Research Tetragonality of Barium Titanate Powder for a Ceramic Capacitor Application. J. Ceram. Process. Res. 2006, 7, 343-354. 
54. Cont, L.; Chateigner, D.; Lutterotti, L.; Ricote, J.; Calzada, M.L.; Mendiola, J. Combined X-Ray Texture-Structure-Microstructure Analysis Applied to Ferroelectric Ultrastructures: A Case Study on $\mathrm{Pb}_{0.76} \mathrm{Ca}_{0.24} \mathrm{TiO}_{3}$. Ferroelectrics 2002, 267, 323-328. [CrossRef]

55. Jiang, B.; Iocozzia, J.; Zhao, L.; Zhang, H.; Harn, Y.W.; Chen, Y.; Lin, Z. Barium Titanate at the Nanoscale: Controlled Synthesis and Dielectric and Ferroelectric Properties. Chem. Soc. Rev. 2019, 48, 1194-1228. [CrossRef] [PubMed]

56. Wada, S.; Yako, K.; Kakemoto, H.; Tsurumi, T.; Kiguchi, T. Enhanced Piezoelectric Properties of Barium Titanate Single Crystals with Different Engineered-Domain Sizes. J. Appl. Phys. 2005, 98, 014109. [CrossRef]

57. Su, C.Y.; Otsuka, Y.; Huang, C.Y.; Hennings, D.F.; Pithan, C.; Shiao, F.T.; Waser, R. Grain Growth and Crystallinity of Ultrafine Barium Titanate Particles Prepared by Various Routes. Ceram. Int. 2013, 39, 6673-6680. [CrossRef]

58. Dixit, A.; Majumder, S.B.; Dobal, P.S.; Katiyar, R.S.; Bhalla, A.S. Phase Transition Studies of Sol-Gel Deposited Barium Zirconate Titanate Thin Films. Thin Solid Films 2004, 447, 284-288. [CrossRef]

59. Scalabrin, A.; Chaves, A.S.; Shim, D.S.; Porto, S.P.S. Temperature Dependence of the A1 and E Optical Phonons in BaTiO 3 . Phys. Stat. Sol. 1977, 79, 731-742. [CrossRef]

60. Hayashi, H.; Nakamura, T.; Ebina, T. In-Situ Raman Spectroscopy of $\mathrm{BaTiO}_{3}$ Particles for Tetragonal-Cubic Transformation. J. Phys. Chem. Solids 2013, 74, 957-962. [CrossRef]

61. Ćirković, J.; Vojisavljević, K.; Nikolić, N.; Vulić, P.; Branković, Z.; Srećković, T.; Branković, G. Dielectric and Ferroelectric Properties of BST Ceramics Obtained by a Hydrothermally Assisted Complex Polymerization Method. Ceram. Int. 2015, 41, 11306-11313. [CrossRef]

62. Woo, K.; Choi, G.J.; Sim, S.J.; Cho, Y.S.; Kim, Y.D. Synthesis and Characteristics of Near-Stoichiometric Barium Titanate Powder by Low Temperature Hydrothermal Reaction Using Titanium Tetra(Methoxyethoxide). J. Mater. Sci. 2000, 35, 4539-4548. [CrossRef]

63. Lee, S.K.; Park, T.J.; Choi, G.J.; Koo, K.K.; Kim, S.W. Effects of KOH/BaTi and Ba/Ti Ratios on Synthesis of BaTiO 3 Powder by Coprecipitation/Hydrothermal Reaction. Mater. Chem. Phys. 2003, 82, 742-749. [CrossRef]

64. Choi, G.J.; Lee Sang, K.; Woo, K.J.; Koo, K.K.; Cho, Y.S. Characteristics of $\mathrm{BaTiO}_{3}$ Particles Prepared by Spray-Coprecipitation Method Using Titanium Acylate-Based Precursors. Chem. Mater. 1998, 10, 4104-4113. [CrossRef]

65. Liao, J.X.; Wei, X.B.; Xu, Z.Q.; Wang, P. Effect of Potassium-Doped Concentration on Structures and Dielectric Performance of Barium-Strontium-Titanate Films. Vacuum 2014, 107, 291-296. [CrossRef]

66. De Andrade, M.C.; Carneiro, G.N.; Moreira, E.L.; Araújo, J.C.; Moraes, V.C.A. Synthesis and Characterization of Barium Titanate by Solid-State Reaction. Mater. Sci. Forum 2014, 802, 285-290. [CrossRef]

67. Ho Han, Y.; Appleby, J.B.; Smyth, D.M. Calcium as an Acceptor Impurity in BaTiO3. J. Am. Ceram. Soc. 1987, 70, 96-100. [CrossRef]

68. Zhou, L.; Vilarinho, P.M.; Baptista, J.L. Solubility of Bismuth Oxide in Barium Titanate. J. Am. Ceram. Soc. 1999, 82, 1064-1066. [CrossRef]

69. Badapanda, T.; Senthil, V.; Rana, D.K.; Panigrahi, S.; Anwar, S. Relaxor Ferroelectric Behavior of "a" Site Deficient Bismuth Doped Barium Titanate Ceramic. J. Electroceramics 2012, 29, 117-124. [CrossRef]

70. Buscaglia, M.T.; Buscaglia, V.; Viviani, M.; Nanni, P.; Hanuskova, M. Influence of Foreign Ions on the $\mathrm{Crystal} \mathrm{Structure} \mathrm{of} \mathrm{BaTiO}_{3}$. J. Eur. Ceram. Soc. 2000, 20, 1997-2007. [CrossRef]

71. Jing, W.A.; Ng, B.; Xu, G.; Liu, Y.; Liu, X.I.; Li, Ã.; Zhao, M. Influence of Doping on Humidity Sensing Properties of Nanocrystalline $\mathrm{BaTiO}_{3}$. J. Mater. Sci. Lett. 1998, 17, 857-859.

72. Strathdee, T.; Luisman, L.; Feteira, A.; Reichmann, K. Ferroelectric-to-Relaxor Crossover in $(1-\mathrm{x}) \mathrm{BaTiO}_{3}-\mathrm{xBiYbO}_{3}(0 \leq \mathrm{x} \leq 0.08)$ Ceramics. J. Am. Ceram. Soc. 2011, 94, 2292-2295. [CrossRef] 